\title{
20 Jahre Mauerfall. Diskurse, Rückbauten, Perspektiven
}

ToRBen LOHMÜLLRR

DAAD/Universidad Complutense

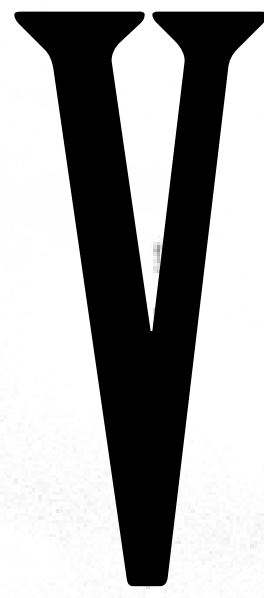

ielerorts stand der vergangene November im Zeichen der Öffnung der Berliner Mauer vor 20 Jahren. In Feiern, Staatsakten und symbolträchtigen Gesten erinnerte man an jene Tage im November 1989, die mit dem Fall der Berliner Mauer schließlich auch das Ende des Kalten Krieges und damit der Aufteilung der nördlichen Hemisphäre in zwei verfeindete Blöcke brachte. Einige sahen damals bereits das Ende der in der liberalistischen Demokratie aufgehobenen Geschichte gekommen, während andere befriedigt feststellten, dass nun endlich zusammenwachse, was zusammen gehöre. Mittlerweile sind beide eines Besseren bzw. Schlechteren belehrt: Der 11. September 2001 markiert den Beginn eines neuen globalen Antagonismus, der r zuweilen eher vor- als nachmoderne Dimensionen angenommen hat, und in Deutschland merkte man schnell, dass

1 der als solcher gefeierte erfolgreiche Beitritt der DDR zur BRD nicht überall so problemlos verlaufen ist, wie es sich viele gewünscht hatten.

I Während öffentliche Feiern ihre Funktion und Berechtigung innerhalb des kulturellen Gedächtnisses haben, dabei aber notwendig in die eine oder andere Richtung vereinfachen müssen, ist es Privileg und Aufgabe der Geistes- und Sozialwissenschaften differenzier252- ter und kritischer hinzusehen. Dazu hatte vom 18. bis 20. November die Universidad Complutense organisiert von Dr. Marta Fernández Bueno(UCM) und Dr. Torben Lohmüller (UCM/DAAD) und mit der Unterstützung des spanischen Ministerio de Ciencia e Innovación, des DAAD, des Goethe Institut Madrid und dem Madrider Germanistenverband (AMG) $\mathrm{zu}$ einer international besetzten germanistischen 
